\title{
REVIEW
}

\section{Clinical review: Thinking outside the box - an iconoclastic view of current practice}

\author{
Mervyn Singer*1 and Michael A Matthay ${ }^{2}$
}

\begin{abstract}
Many advances in medicine have been achieved through challenging established dogma with revolutionary thought and novel practices. Each and every specialty is reinvigorated by regular re-evaluation of processes and practices in the light of new evidence and fresh conceptualization. Challenge can galvanize fresh thinking and new approaches, yet may also reinforce and strengthen traditional paradigms if the prevailing orthodoxy is subsequently revalidated. This article is a synopsis of a roundtable meeting held in Brussels in March 2010 designed specifically to confront doctrine with reasoned scientific argument, and to propose new ideas for advancing critical care practices and outcomes.
\end{abstract}

\section{Introduction}

\section{"In all affairs, it's a healthy thing now and then to hang a question mark on the things you have long taken for granted."}

Bertrand Russell

The roundtable meeting held in Brussels in March 2010 was designed specifically to challenge established dogma and evaluate new ideas for advancing critical care practice. Participants submitted provocative and iconoclastic ideas, offering a broad sweep of ideas involving changes in specific practices, new concepts in the process of care delivery, and paradigm shifts with regard to understanding of critical illness and current management approaches. The rules were simple; a scientific basis had to be offered to underpin assertions with subsequent debate impelling defence or modification of the stance.

*Correspondence: m.singer@ucl.ac.uk

'Bloomsbury Institute of Intensive Care Medicine, Department of Medicine, University College London, London WC1E 6BT, UK

Full list of author information is available at the end of the article
Some of these hypotheses may turn out to be misguided and others will require more refinement and evaluation. We are nevertheless grateful to the participants listed at the end of this article for raising their heads above the parapet and making us 'think outside the box'. This article summarizes the potpourri of novel thinking offered at the meeting. For more depth, we refer you to the individual articles provided in a supplement of Critical Care Medicine.

\section{Have we got the right constructs?}

A disease is a process of deranged physiological or biochemical function, often with an identifiable cause and a pathological signature. However, critical illness with its syndromic manifestations (for example, acute respiratory distress syndrome (ARDS), sepsis) are often deliberate consequences of the aggressive interventions inflicted upon patients to save their lives, rather than simply the natural progression of the precipitating condition. For instance, fluid resuscitation restores organ perfusion in severe haemorrhage but, due to increased capillary permeability, may be at the cost of pulmonary oedema with compromised lung function. Subsequent sedation, intubation and mechanical ventilation may, in turn, produce haemodynamic, immune and other perturbations with increased risks of secondary infection, muscle wasting and delirium. Antibiotic therapy, combined with routinely prescribed gastric protectants, will alter gut colonization patterns and trigger further infections, systemic inflammatory surges through micro-aspiration and gut translocation, and/or bouts of diarrhoea. The consequent inability to establish enteral nutrition may aggravate muscle wasting and compromise weaning.

This patient, presenting with a 'simple' gastrointestinal bleed, has spiralled out of control into multiple organ dysfunction. If critical illness itself is acknowledged as being, in many instances, an intrinsically iatrogenic disorder shaped and defined by the same interventions used to sustain life, then better means of prevention or disease modification could be delineated. The implications of an iatrogenic model of critical illness extend beyond checklists and management bundles, and suggest the need for nuanced changes in approach, not only in managing critical illness, but in how we describe it. A primary 
research focus should be on minimization of harm rather than optimization of benefit, a subtle but important shift in approach.

Patients should also be considered in terms of their individual response to an external stressor, rather than coalescing them into broad populations. This point will be revisited later in terms of trial design but we should recognize how differences in genotype, age, comorbidity and environmental factors all combine uniquely within an individual patient to dictate the degree of systemic inflammatory response, not only to the stressor but also to the raft of therapeutic interventions delivered.

Epidemiological studies suggest that sepsis-related mortality is decreasing, though perhaps not as much as anticipated from advances in resuscitation strategies, supportive techniques, and general improvements in process of care. This implies that relatively constant pathways still lead to death in many patients, regardless of our improved ability to reverse shock, oxygenate and feed. The magnitude of the individual's biological response also appears to dictate prognosis, even at an early stage of their critical illness. Many studies (for example, [1-4]), albeit predominantly single-centre and limited in size, have predicted outcome using laboratory or physiological measures made soon after ICU admission, or even in the Emergency Department. Biomarkers range from polymorphisms to altered gene expression profiles, and from circulating cytokine levels to a variety of hormones, metabolites and markers of immune function, endothelial and epithelial injury, and coagulopathy.

Confirmation in larger populations will carry important implications. If death is largely predetermined and critical care is simply delaying the inevitable, should we not direct resources elsewhere, sparing the patient and their loved ones unnecessary suffering and false hope? Should we be re-designing intervention studies that have a primary endpoint of survival to focus primarily on patients predicted to die? Apart from making large multicentre trials more manageable in terms of sample size, those predicted to live cannot benefit further, at least not in terms of survival, which can only be compromised by treatment side effects. How does the time to death relate to underlying predisposition? Should patients dying early or late from a particular condition be considered separately? Deaths occurring soon after the onset of a shock condition will differ mechanistically from late deaths occurring weeks later that may relate to secondary complications or therapeutic fatigue after no apparent recovery? Perhaps early deaths may require a therapeutic approach aimed at combating pathogen virulence and modifying the cellular predisposition response identified by rapid biomarker tests, whereas patients with a recognized predisposition for late-onset death may benefit from strategies that accelerate mechanisms involved in recovery and healing, and that minimize interventions hindering recovery, for example, sedatives?

\section{Novel diagnostics}

Traditionally, the plasma compartment is predominantly used to measure drug concentrations to establish pharmacokinetics and dosing regimens, and for biological markers to establish diagnosis and treatment response. However, the most relevant concentration of both small and large molecules occurs in the pericellular environment, so this should be preferentially targeted. Based on experience gained with markers of tissue oxygenation, interstitial concentrations can be measured using probes and solid-state sensors sited percutaneously or inserted into subcutaneous tissue [5], fat or muscle. Microdialytic methods can measure glucose, antibiotic concentrations, lactate, pyruvate and other biologically important molecules [6]. The normal electrolyte, protein, gas and $\mathrm{pH}$ compositions of the interstitial space differ from plasma and may offer more appropriate targets. Would interstitial free cortisol concentrations direct replacement therapy better than either free or total (including protein-bound) plasma cortisol [7]? Would interstitial antibiotic concentrations be more appropriate [8]?

Another useful diagnostic would be to determine bacterial load and virulence. Current microbiological testing for pneumonia relies primarily upon blood cultures and microscopic examination and culture of tracheal/bronchoalveolar aspirates. The time-frame for these analyses ranges from 12 to 48 hours. Newer molecular diagnostics will enable more rapid acquisition of data. Quantitative assessment of bacterial load may be be a useful prognosticator. This is routinely performed for HIV and could be readily extended to bacterial pneumonia. Associations are reported between a high load of Streptococcus pneumoniae in blood samples, increased sepsis severity and higher mortality [9]. Regular testing of bacterial load may be used to assess treatment response. Virulence factors could also be measured, particularly for S. pneumoniae, Staphylococcus aureus, and Pseudomonas aeruginosa, to determine whether antibiotic therapy is actually needed in the first place, or whether the patient may benefit from either a more limited or more prolonged course of treatment.

Similarly, viral infection should be sought more aggressively. Whereas latent cytomegalovirus (CMV) is harmlessly present in 60 to $70 \%$ of healthy people, reactivation is associated with substantial morbidity and mortality in the immunocompromised host. However, CMV may be a common infecting organism in critically ill patients not formally recognized as immunocompromised, although they usually exhibit evidence of depressed immune function, if sought [10]. CMV infection may be an important confounding factor in 
culture-negative sepsis for which antibacterials are inappropriately prescribed. Future severe sepsis trials should prospectively consider active CMV infection as a relevant covariate.

A more radical approach to diagnosing disease relies on the fact that biological systems are highly complex yet, in health, display seemingly chaotic behaviour patterns that are actually predictable in their intrinsic variability. These patterns change in disease states and, with modern computer and modelling technology, would be detected far sooner than conventional physiological or biochemical variables.

A major benefit of complexity within a system is its ability to self-organize. This occurs spontaneously and offers robustness and resilience such that a single point of failure rarely results in total system failure. An adaptive system finds an acceptable alternative promptly as decisions need to be taken while they are still relevant. This ability to adapt offers a survival advantage in a changing environment. Traditionally, disease is considered to cause marked fluctuations in the body's systems; however, studies using complexity theory demonstrate the opposite, with loss of chaos and increasingly constant behaviour. Arguably, disease reflects a loss of the ability to adapt adequately (see discussion on allostasis in the 'Decatecholaminization' section below). External stressors - for example, exercise, temperature change and anxiety - decrease the intrinsic variance of many biological systems such as immune, vascular and limbic. Indeed, death is the ultimately stable and static condition. Loss of normal heart rate variability, used frequently as a measure of decreased biological fluctuation, occurs in acute illnesses such as myocardial infarction [11], brain injury [12] and sepsis [13]; the degree of loss is strongly associated with mortality.

This approach may offer a powerful tool to define determinants of instability, to determine why disease is unhealthy, and to identify potentially effective treatment options regardless of known pharmacology and physiology. Without even fully understanding the processes underlying a disease, treatments that restore a 'healthy' pattern may be effective.

\section{Managing respiratory failure}

Although lung-protective ventilation with low tidal volumes and lower plateau airway pressures has markedly improved outcomes in acute lung injury, any type of positive pressure ventilation may be detrimental. However, is positive pressure ventilation generally safe? Should we be pressing harder for alternatives? The former viewpoint challenges the mantra that mechanical ventilation is invariably harmful and that a safe limit for airway pressure may not even exist. Though now firmly enshrined in the literature, this dogma does not appear to be based on hard fact. Many questions require answers. Does lung damage develop proportionally to the stress/ strain applied (for example, transpulmonary or plateau pressure, or tidal volume), or only when a critical threshold is exceeded? What is the role, if any, of ventilatory rate, the application of stress/strain over time, in causing ventilator-induced lung injury? In terms of biological response, does it matter whether a given stress/ strain is applied intermittently as with tidal ventilation, or continuously with positive end-expiratory pressure (PEEP)? Though often considered separately in trial design, end-inspiratory and end-expiratory stresses and strains are interwoven; the amount of lung tissue remaining open at end-expiration, or that undergoes intra-tidal opening and closing, depends on tidal volumes being delivered, corresponding inspiratory pressures, and the degree of pulmonary consolidation and atelectasis.

The validity of heterogenous randomized controlled trials (RCTs) in acute lung injury can be challenged. While low tidal volume ventilation is promoted as 'standard-of-care', this carries its own risks, including overuse of sedative drugs and formation of atelectasis, especially when applied to patients who could otherwise tolerate higher volumes. Because of the heterogeneity of the acute lung injury (ALI)/ARDS population, tidal volume should be tailored to the specific characteristics of each individual patient. As ventilator-induced lung injury can only occur in open lung units, knowledge of the actual size of each patient's 'baby lung' is vital so that delivered tidal volumes do not expand the baby lung to or beyond its total capacity. In this situation, mechanical ventilation is likely to be safe. However, in a limited number of patients total capacity may be exceeded by tidal volumes as low as $6 \mathrm{ml} / \mathrm{kg}$; subsequent overdistention may be injurious [14]. Likewise, PEEP may be protective provided it keeps open lung regions that would otherwise collapse at end-expiration. In the absence of lung recruitability, however, PEEP may solely increase stress/strain with no benefit or even harm to the patient. Notwithstanding this, as a general rule unsafe limits of end-inspiratory and end-expiratory stress/strain are uncommonly reached in the ALI/ARDS population overall.

A strong counter-argument runs that positive pressure breathing itself contributes directly to lung trauma, haemodynamic perturbations and local and systemic cytokine responses. The need to sedate, immobilize, suppress cough and insert endotracheal tubes upon which biofilms develop will all predispose to infection. Application of extrapulmonary gas exchange techniques have generally focused upon their use as a rescue therapy for severe hypoxaemia. This requires high blood flows (up to $5 \mathrm{~L} /$ minute) and correspondingly demanding vascular access to add only a quarter or so of the total 
carrying capacity of oxygen. By contrast, $\mathrm{CO}_{2}$ removal requires low blood flows but a high flow of fresh gas. In theory, only $500 \mathrm{ml}$ of blood needs to be treated per minute to completely replace the lung's role for $\mathrm{CO}_{2}$ elimination as this volume contains the amount of $\mathrm{CO}_{2}$ equivalent to that of a minute's production by body metabolism. This target could be achieved through removing sodium bicarbonate by ultrafiltration and replacing it with sodium hydroxide [15]. Alternatively, blood could be loaded with a metabolisable acid (such as lactic acid) to convert bicarbonate ion to carbonic acid that, in turn, would dissociate to dissolved $\mathrm{CO}_{2}$ [16]. By substantially increasing $\mathrm{CO}_{2}$ tensions on the blood side of the extracorporeal membrane, the gradient for passive transfer of $\mathrm{CO}_{2}$ to the gas compartment would be markedly increased.

It may be feasible and safe to institute extracorporeal carbon dioxide removal at a much earlier stage to control ventilatory needs, allow acceptable levels of arterial blood gases and $\mathrm{pH}$ with spontaneous breathing with or without continuous positive airway pressure, and to avoid the need for intubation and heavy sedation. By removing $\mathrm{CO}_{2}$ independent of alveolar ventilation, mechanical ventilatory requirements will be significantly decreased. The $\mathrm{CO}_{2}$ dialysis-like system would only need to be comparable in complexity and invasiveness to continuous renal replacement therapy [17].

Sedated, ventilated patients are traditionally rolled or rotated to prevent pressure sores and to facilitate therapeutic postural drainage. However, in the early phase of an acute, suppurative, unilateral bacterial pneumonia, secretions may spill over to the contralateral lung, extending the pneumonia and lung injury to previously uninvolved lung segments $[18,19]$. Arguably, the lung has evolved in distinct segments to trap infection and prevent spread through local consolidation and obstruction of airways. Once bacteria have been phagocytosed and cleared, the debris can be more safely expectorated. We should perhaps avoid gravitational drainage of secretions from one infected lung (or region thereof) into unaffected lung zones, particularly in the first 24 to 48 hours.

Furthermore, small tidal volumes, associated with lower peak expiratory flows, tend to limit proximal expulsion of biological fluids. Larger tidal volumes and forceful exhalation increase peak flows, creating an expiratory flow bias that could encourage migration of secretions to the trachea and possible cross-aspiration [20]. The value of maintaining infected lung zones in a dependent position plus the use of smaller tidal volumes and higher PEEP levels to prevent propagation of inflammatory and infected secretions probably declines over 2 to 3 days due to transformation of mobile and inflammatory oedema fluid to more pro-coagulant and gelatinous secretions.

\section{Off-the-wall therapies}

Cell-based therapy can repair or replace damaged tissues. Recent preclinical studies suggest that allogeneic mesenchymal stem cells may have therapeutic value for sepsis and ALI $[21,22]$. Outcome benefit currently appears to depend primarily upon secreted paracrine factors, including anti-inflammatory cytokines, growth factors and other molecules that decrease tissue injury and/or enhance repair. To date, allogeneic mesenchymal stem cells have been given to over 2,000 patients by Osiris Therapeutics, Inc. (Baltimore, MD, USA) with no serious safety issues. The safety of giving allogeneic mesenchymal stem cells to patients one month post-myocardial infarction was recently demonstrated with some limited, albeit statistically significant, evidence for improvement in cardiac rhythm disorders and cardiac function [23]. A cautious, step-by-step approach is needed, including further preclinical work to determine mechanisms of action, optimal delivery systems and dosing regimens, plus carefully performed clinical trials.

Another novel approach is giving oestrogen, either as a therapeutic or a preventative strategy. Oestrogen offers anti-inflammatory, anti-apoptotic and anti-oxidant effects that may be beneficial in ischaemic and inflammatory insults. Oestrogen protects mitochondria and can stimulate mitochondrial biogenesis. Epidemiological studies suggest that women of childbearing age fare better after cardiac arrest and trauma, with loss of this advantage after the menopause [24]. Considerable preclinical data show that oestrogen may be an effective intervention for a spectrum of severe physiological insults - for example, multiple trauma, head and spinal cord injury, burns, and sepsis (for example, [25,26]). Clinical studies are currently ongoing to verify the efficacy of oestrogen in severely head-injured patients with and without haemodynamic compromise.

What about hyperoxia as a therapy? While physicians fret about high concentrations of inspired oxygen and the potential for harm, animal data suggest that ventilation with $100 \%$ oxygen as a supportive measure during the first 12 to 24 hours of septic shock may be beneficial, and that pulmonary toxicity is not an issue [27,28]. Pure oxygen ventilation induces peripheral vasoconstriction; while this may affect regional perfusion, it could counteract shock-induced hypotension and reduce vasopressor requirements. Tissue hypoxia has a marked proinflammatory effect while hyperoxia is anti-inflammatory, for example, attenuating nuclear factor kappa-B activation, lowering expression of endothelial adhesion molecules, decreasing leukocyte rolling and adherence, reducing release of IL-6 and HMG-B1, and increasing production of the anti-inflammatory IL-10. While hyperoxia may increase reactive oxygen species production, resulting in oxidative damage, contradictory data show that hyperoxia 
can trigger repair mechanisms and increase antioxidant capacity. Though studies are conflicting, hyperoxia can reduce the incidence of postoperative wound infections [29], probably through an antibiocidal effect as oxygen is crucial for phagocyte-dependent microbial killing via reactive oxygen species [30,31]. Hyperoxic preconditioning can also reduce apoptosis [32]. Hyperoxia may not simply be the 'bad guy', as largely viewed at present. Further studies are warranted in selected patient groups to assess safety and benefit, and how it should be best employed.

\section{Decatecholaminization}

Are catecholamines safe? Is there detriment from pushing blood pressure (BP) too high? Should patients remain in a stressed state driven by both endogenous and exogenous catecholamines? Should patients be 'decatecholaminized' with greater emphasis on catecholamine dose reductions, targeted use of beta-blockade and general de-stressing?

Critically ill patients are frequently treated with catecholamines, yet these drugs have deleterious effects on immune function, thrombogenicity and metabolic efficiency, on stimulating bacterial growth, and on causing myocardial injury [33]. Guidelines recommend mean BP values $\geq 65 \mathrm{mmHg}$ for patients with severe sepsis, albeit with no firm scientific basis. However, data from septic shock studies indicate that these pressure targets are regularly exceeded, often by $\geq 20 \mathrm{mmHg}$ [34]. Higher mortality was noted in those where higher mean BP values were generated using progressively higher catecholamine doses [34]. Over-adjustment of BP and unnecessary vasopressor use may thus harm. Studies are needed to re-evaluate the lowest tolerable BP in patients with severe sepsis, acknowledging this will vary between patients.

Because septic patients are often vasodilated and hypotensive, beta-blockers are traditionally not used. However, preclinical studies demonstrate that beta-blockers reduce the inflammatory response and the degree of lung injury without creating further hypotension [35]. Furthermore, they can prevent down-regulation of adrenergic receptors, thus preserving cardiac function, and improving outcomes [35,36]. In limited studies in septic patients, beta-blockade compromised neither oxygen utilization, ATP availability, nor the macrocirculation $[37,38]$. Studies are needed to establish the safety and efficacy of beta-blockade in the critically ill, and to assess alternative vasopressors.

These concepts tie in well with the paradigm of allostasis $[39,40]$ and its applicability to critical care. Allostasis is an adaptive phenomenon whereby the body adjusts and adapts itself to various stressors (for example, exercise, emotion, hunger) to maintain homeostasis in systems essential for life. More stress will increase allostatic load, placing greater pressure on these adaptive systems. Severe and/or prolonged stress can result in allostatic overload, a decompensation with pathological effects on various systems, for example, immune, hormonal, metabolic, cardiovascular and gut. High sympathetic overload is core to this systemic deterioration. Several examples exist, including Takotsubo cardiomyopathy, a heart failure condition associated with high catecholamine levels yet normal coronary arteries that can follow acute emotional stress but which responds to beta-blockade [41].

Similar concepts to allostasis have been described over the past 70 to 80 years. For example, Selye [42] described how severe, prolonged stress leads to 'organ distress'. With relevance to critical illness, the body attempts to deal with 'type I allostatic overload', where metabolic demands exceed supply, by entering a state of metabolic shutdown to restore the energy imbalance. This hibernatory-type condition may represent an important pathological process underlying multi-organ failure [43]. Apart from avoiding catecholamines where possible, and considering beta-blockade, we should also recognize and act upon other commonplace stressors suffered by ICU patients, including sleep deprivation [44], pain, boredom, and communication problems.

\section{The animated ICU - preparing for survival}

Reduced time on mechanical ventilation, shorter lengths of stay and survival benefit are demonstrated through more judicious use of sedation. Likewise, the incidence of ICU delirium, a risk factor associated with poor outcomes, long-term cognitive impairment and behavioural problems, is also significantly reduced [45]. Apart from simply re-evaluating sedation requirements on a regular basis, we must address the broader picture of recognizing delirium in both agitated and hypo-agitated forms, plus preventing and treating it through a three-step approach of screening, prevention and restoration of brain function. Prevention of acute and chronic brain dysfunction requires implementation of an 'ABCDE' core model of care focusing on Awakening and Breathing, Coordination with target-based sedation (and Choice of sedative), Delirium monitoring, and Exercise/Early mobilization. Treatment should not stop on ICU discharge. A continuing program of regular neuropsychological screening with active intervention is needed for survivors at high risk of ongoing brain dysfunction. This includes cognitive and physical rehabilitation directed towards improving executive and memory deficits. While no specific drug therapies have yet been trialled in ICU survivors, some possibilities do exist, for example, cholinesterase inhibitors that are currently used in dementia [46].

It is not solely the brain that needs active protection and support. As we have frequently highlighted, the 
various impacts of ICU treatments extend beyond keeping the patient alive. They actively contribute towards critical illness in its assorted guises [47] and have implications not just for the short term, in terms of ICU survival, but also for long-term quality and quantity of life. Traditionally, patients have been kept immobilized as a necessary evil to facilitate support technologies such as mechanical ventilation. However, this long-standing dogma is unfounded, or at least overplayed, as increasing awareness of the adverse effects of immobilisation become increasingly apparent. Apart from the issues surrounding sedation described earlier, there is an increased risk of nosocomial infection, pressure sores, joint contractures, muscle wasting and weakness. These iatrogenic complications hinder recovery and contribute to late-onset deaths. With the advent of more sophisticated, synchronisable ventilators that enable comfortable modes of spontaneous breathing, there is a dwindling need to apply neuromuscular blockade and maintain extreme immobilization. With the ventilated patient being awake and cooperative, physiotherapy involving active mobilization can be instituted earlier, expediting the recovery process [48]. New drug approaches could be implemented - for example, the mureceptor antagonist methylnaltrexone to block the peripheral, non-analgesic actions of opiates [49], or increased use of the opiate-sparing, less sedating alpha ${ }_{2}$ adrenergic agonist dexmedetomidine [50].

In addition to early reanimation, can recovery from muscle wasting be facilitated? The incidence of ICUacquired bilateral symmetrical limb weakness was 50\% at the time of wakening in patients mechanically ventilated for 7 days or more, and persisted in half of these patients a week later [51]. This limb weakness is associated with delayed weaning. Potential strategies to decrease muscle weakness include either anti-atrophy agents or prohypertrophy agents. Muscle-specific ubiquitin ligases such as MuRF1 and Atrogin-1 could be targeted as these are essential for muscle atrophy [52], while testosterone or myostatin inhibitors could be assessed for their hypertrophic effects [53]. For non-pharmacological strategies, apart from re-training, neuromuscular electrical stimulation may prove a useful rehabilitation tool [54].

\section{Randomized clinical trials - reappraised}

Most of the large multicentre 'phase III' trials over the past 15 years have been negative, with no significant differences shown between treatment and placebo groups, even when powered adequately [55]. In only $10 \%$ or so was the intervention beneficial, while a similar percentage indicated harm, despite a seemingly sound biological rationale. Flaws in study design have obviously contributed in many cases. Yet, these repeated failures may have concealed patient subsets that benefited yet were diluted out by non-responders, or even counterbalanced by subsets that were harmed.

The concept of lumping patients by 'syndrome' is outdated. More homogeneous patient groups should be studied - for example, those with ALI related to an infectious cause - rather than enrolling all-comers who fulfil radiological and physiological criteria but include non-infectious aetiologies such as trauma or aspiration. For sepsis trials, enrolment has previously relied upon physiological and biochemical criteria, but greater efforts should be made to identify the patient's immunological/ biological phenotype to reduce heterogeneity. Rather than fixed dosing regimens, treatments should be titrated to the individual. This will depend on the particular phenotype being modulated, not only in terms of dosage but also in the timing of commencement and cessation of the intervention. While sepsis trials often enrol patients on the basis of number of organ failures accrued, acute physiology only contributes a third of the explanatory power of outcome prediction; predisposition of the patient (for example, cancer, diabetes, heart failure) accounts for nearly half [56]. The Predisposition, Insult/ infection, Response, and Organ dysfunction (PIRO) concept of risk assessment may prove more useful than APACHE (Acute Physiology and Chronic Health Evaluation) or SOFA (Sequential Organ Failure Assessment) scores for enrolment and stratification [57].

A stepwise approach is needed before commencing large phase III RCTs. This will enhance understanding of underlying mechanisms and will justify the time, expense and validity of assessing the intervention in a clinical setting. Biological plausibility needs to be demonstrated with supportive animal data from more than one species and using more than one model of disease that needs to be both representative of the human condition and with appropriate timing of the intervention. Human models of critical illness should also be considered, for example, low dose endotoxin challenge administered to volunteers, endotoxin installation into lung specimens resected for cancer, ex vivo perfused human lung preparations, or pulmonary inflammation following coronary artery bypass surgery or with one lung ventilation in the setting of lung resection or oesophagectomy. Such models have a limited ability to provide data on surrogate clinical outcomes or safety, but can help determine whether a putative therapy can modulate pathologically relevant mechanisms.

More phase II exploratory trials are thus needed to firmly establish a sound rationale. High-quality proof-ofconcept studies should be supported by assessment of the impact on mechanistically relevant surrogate biomarkers. Ideally, such studies should only be undertaken in a limited number of ICUs to control the potential confounding effect of variations in standard 
practice. Conservative estimates of treatment effect size should be adopted when planning larger phase II studies to confirm efficacy for clinically important endpoints, to better determine treatment effects, to support the biological rationale underpinning the intervention, to support safety data, and to better inform sample size calculations, feasibility and design for subsequent phase III trials.

Observational studies, oft-criticized and dismissed as merely hypothesis-generating, may also offer more than currently believed. Findings are generalisable to 'real life' practice as entire patient populations can be enrolled without exclusion. Informed consent is usually unnecessary, allowing prompt and relatively inexpensive enrolment of large patient numbers. They can only demonstrate association and are open to the possibilities of bias, confounding and reverse causality, and of overestimating the beneficial effects of treatments. However, results obtained from some observational studies and RCTs comparing the same treatments have reported similar estimates of treatment effect $[58,59]$.

The large RCT is still needed, albeit with refinements such as those described above that will enhance the likelihood of success. Increasing awareness of their limitations within the critical care setting and inherent difficulties in recruiting sufficient numbers of tightly defined patients will, by necessity, require incorporation of other forms of evidence. The challenge lies in steering an appropriate course, not over-extrapolating trial results to the ICU population in general, and focusing clinical trials on a strong biological rationale.

\section{Process of care - what should we be doing differently?}

We should re-examine current processes of care. At one level this could relate to removal or reduction of unnecessary and costly procedures and interventions - do patients need routine daily chest X-rays or whole-body 'diagnostic' CT scans with liberal use of nephropathic dyes? Do they need routine arterial and central venous cannulation? There is also the bigger picture that needs to address the burgeoning demand for, and cost of, critical care. Particularly in the US, intensive care provision is regarded as an individual patient decision, even when futile. Some ethicists and clinicians would argue this is an inalienable human right. However, in these straightened economic times when ICUs are often struggling to fill staffing rosters, critical care can no longer be viewed as an unlimited resource. Delivery of futile care can occur at the expense of others, even in the absence of resource limitation. For example, antibiotic resistance is encouraged through aggressive treatment of infection in patients receiving futile care. 'Never events', such as catheter-related sepsis and pressure sores, can readily occur in patients with serious underlying illnesses whose lives are being prolonged by futile care. The threat that insurance payers will withhold funding after such an event means that the hospital will have less finance to treat other patients without futile illness. Clearly, we should discriminate between futile and marginal care, but we should not shy away from this important issue.

Likewise, the concept of care bundles merits further scrutiny. A bundle represents a number of separate interventions packaged together and promoted as best practice. ICUs should be standardizing many aspects of critical care management, taking into account local factors such as staffing levels, expertise, facilities, specific infections and patient case mix. High compliance rates should be mandated, with performance and outcomes routinely audited to support likely benefit and exclude obvious harm to the patient population as a whole. However, should there be a headlong rush to instigate specific packages as standards of care using positive outcome studies of varying quality? No attempt has been made to formally validate each bundle as a whole, nor to acknowledge the often weighty degree of contradictory data. Findings are being extrapolated to patient subsets that are often quite distinct from those in whom they were generated. Furthermore, what may be appropriate management at one timepoint in the patient's critical illness may be inappropriate at another. There is often minimal regard of the context in which the underlying evidence was generated, and the problems created by differences between efficacy (what works in the best possible hands/circumstances) and effectiveness (what works in 'real life'). Increasing pressure is now being exerted by governmental bodies, healthcare funders and patient safety groups to fast-track their implementation. Instead of the clinical practice improvements for which they were originally intended, there is increasing anxiety that care bundles will be used inappropriately as a quality control marker for ICU benchmarking, with medicolegal and reimbursement ramifications. If you do not implement a proscribed bundle of measures, are you a bad ICU that should be penalized?

The challenge lies in when to deviate outside guidelines and protocols. What may benefit a population in general terms may be disadvantageous to an individual at a certain point in time. For example, should enteral nutrition be attempted, or even forced using prokinetics, when the gut manifests signs of intolerance (high aspirates, abdominal distention, diarrhoea) [60]? Mortality in such patients is considerably higher. Is this gut dysfunction simply reflective of a sicker patient or do we contribute directly to poor outcomes by attempting to force-feed an unhappy bowel?

Smoothing out inconsistency is one of the original, and still most potent, arguments for care bundles. 
Inconsistency continues to dominate much of our decision-making and is likely to impact negatively upon patient outcomes. The patchy uptake of evidence into daily practice suggests inherent prejudices that are often difficult to surmount. Applying behavioural psychology will expose our cognitive biases, facilitate use of data and deliver a more consistent and less stressful series of decisions to the benefit of both patient and caregiver. Choice depends on information, the framing of which the 'task environment' - will influence decision-making.

Judgment combines processing of information and estimation of probabilities. Intuitive judgments (heuristics) are mental shortcuts that allow simplification of complex problems, providing quick solutions at relatively low cognitive cost. Clinicians use heuristics to aid diagnosis; examples include pattern recognition and 'indexing keys' that associate elements of history and physical examination to specific conditions. However, this can lead to errors in judgment, or biases, for example, not considering all possible options or by introducing a preference for one. Importantly, heuristics tend to dominate when the clinician is fatigued or under time pressure. Knowledge, attitudes and incentives do relatively little to disrupt these instinctive cognitive strategies. Individuals can overcome their heuristic tendencies if information is made easier to use, and if they have to explicitly construct rule-based analyses to problem-solve. Training will make people aware of their own biases and can instil rule-based behaviour through repetitive practice with feedback. Standardizing ICU care requires compensation of cognitive biases and restructuring of the task environment to make the easy choice the right one. Behavioural psychology can provide important insights into these biases and could readily be utilized to improve the quality of delivered care.

Apart from self-improvement, we should also reduce 'machine friction' in the system by improving on organizational underperformance. A focus on simple, readily implementable process-of-care measures will deliver greater patient outcome benefit, and at lesser cost, than many technological advances of recent years. Variations in performance between ICUs are not simply due to differences in case mix and facilities, but also to variations in process and behaviour patterns. With regard to the above debate over protocolised care and bundles, a reasonable middle ground is to avoid extremes and acknowledge that protocolisation is likely to benefit some elements of routine practice, whereas an individualized approach is needed for others. The balance will, however, vary between ICUs depending on staffing, available expertise, case mix, and other factors.

Certain 'givens' are mandated in oiling the wheels. Apart from effective education to inform decisionmaking, management plans must be communicated to, and delivered by, the rest of the 'machine' both inside and outside the ICU. At each interface there is the opportunity for success or a potentially compromising friction. This applies to interactions between day and night shifts, between multi-disciplinary care team members, and with external specialists. Studies have shown outcome improvements simply by an ICU physician doing daily rounds [61]. Error in all its forms should be understood and minimized. Again, poor communication is often at fault but institution of simple procedures such as checklists, daily goals, feedback of compliance rates, and non-blame error reporting will contribute to more effective delivery of care. We must foster a culture in which junior members and multi-disciplinary colleagues feel they can voice concerns and opinions. Importantly, we need to lead in the overall sense, a skill for which specific training is rarely, if ever, provided.

\section{Conclusion}

We hope this article has provided some new food for thought. We neither expect nor demand immediate implementation but rather a re-consideration of current practices, a re-evaluation of available evidence, and effective testing to confirm or refute the validity of the proposed hypotheses.

\begin{abstract}
Abbreviations
ALI, acute lung injury; ARDS, acute respiratory distress syndrome; $B P$, blood pressure; CMV, cytomegalovirus; IL, interleukin; PEEP, positive end-expiratory pressure; $\mathrm{RCT}$, randomized controlled trial.
\end{abstract}

\section{Competing interests}

The authors declare that they have no competing interests.

\section{Acknowledgements}

This work was undertaken in part at UCLH/UCL, which receives a proportion of its funding from the UK Department of Health's NIHR Biomedical Research Centre's funding scheme. We would like to thank the contributors to the 2010 Brussels Round Table for their imagination and input: Derek Angus (Pittsburgh, USA), Stephen Brett (London, UK), Wes Ely (Nashville, USA), Luciano Gattinoni (Milan, Italy), Jesse Hall (Chicago, USA), Nick Hart (London, UK), Andre Kalil (Omaha, USA), John Marini (St Paul, USA), John Marshall (Toronto, Canada), Michael Matthay (San Francisco, USA), Danny McAuley (Belfast, UK), Rui Moreno (Lisbon, Portugal), Michael Niederman (Mineola, USA), Didier Payen (Paris, France), Paul Pepe (Dallas, USA), Antonio Pesenti (Milan, Italy), Michael Pinsky (Pittsburgh, USA), Peter Radermacher (Ulm, Germany), Marco Ranieri (Turin, Italy), Jordi Rello (Tarragona, Spain), Alain Rudiger (Zurich, Switzerland), Mervyn Singer (London, UK), Jukka Takala (Basel, Switzerland), Bala Venkatesh (Woollongabba, Australia), Jean-Louis Vincent (Brussels, Belgium), Julia Wendon (London, UK)

\section{Author details}

'Bloomsbury Institute of Intensive Care Medicine, Department of Medicine, University College London, London WC1E 6BT, UK. ²Departments of Medicine, Anesthesia, and the Cardiovascular (MAM), Research Institute at the University of California, San Francisco, CA 94143, USA.

\section{Published: 26 July 2011}

\section{References}

1. Rothwell PM, Lawler PG: Prediction of outcome in intensive care patients using endocrine parameters. Crit Care Med 1995, 23:78-83.

2. Annane D, Sébille V, Troché G, Raphaël JC, Gajdos P, Bellissant E: A 3-level prognostic classification in septic shock based on cortisol levels and 
cortisol response to corticotropin. JAMA 2000, 283:1038-1045.

3. Hynninen M, Pettilä V, Takkunen O, Orko R, Jansson SE, Kuusela P, Renkonen R, Valtonen M: Predictive value of monocyte histocompatibility leukocyte antigen-DR expression and plasma interleukin- 4 and - 10 levels in critically ill patients with sepsis. Shock 2003, 20:1-4

4. Levy B, Dusang B, Annane D, Gibot S, Bollaert PE; College Interregional des Réanimateurs du Nord-Est: Cardiovascular response to dopamine and early prediction of outcome in septic shock: A prospective multiple-center study. Crit Care Med 2005, 33:2172-2177.

5. Venkatesh B, Morgan TJ, Lipman J: Subcutaneous oxygen tensions provide similar information to ileal luminal $\mathrm{CO}_{2}$ tensions in an animal model of haemorrhagic shock. Intensive Care Med 2000, 26:592-600.

6. Nandi P, Lunte SM: Recent trends in microdialysis sampling integrated with conventional and microanalytical systems for monitoring biological events: A review. Anal Chim Acta 2009, 651:1-14.

7. Cohen J, Venkatesh B: Assessment of tissue cortisol activity. Crit Care ResusC 2009, 11:287-289.

8. Zeitlinger MA, Dehghanyar P, Mayer BX, Schenk BS, Neckel U, Heinz G, Georgopoulos A, Müller M, Joukhadar C: Relevance of soft-tissue penetration by levofloxacin for target site bacterial killing in patients with sepsis. Antimicrob Agents Chemother 2003, 47:3548-3553.

9. Rello J, Lisboa T, Lujan M, Gallego M, Kee C, Kay I, Lopez D, Waterer GW: DNA-Neumococo Study Group: Severity of pneumococcal pneumonia associated with genomic bacterial load. Chest 2009, 136:832-840

10. Kalil AC, Florescu DF: Prevalence and mortality associated with cytomegalovirus infection in nonimmunosuppressed patients in the intensive care unit. Crit Care Med 2009, 37:2350-2358.

11. Pipilis $\mathrm{A}$, Flather $\mathrm{M}$, Ormerod $\mathrm{O}$, Sleight $\mathrm{P}$ : Heart rate variability in acute myocardial infarction and its association with infarct site and clinical course. Am J Cardiol 1991, 67:1137-1139.

12. Papaioannou V, Giannakou M, Maglaveras N, Sofianos E, Giala M: Investigation of heart rate and blood pressure variability, baroreflex sensitivity, and approximate entropy in acute brain injury patients. J Crit Care 2008, 23:380-386

13. Chen $\mathrm{WL}$, Chen $\mathrm{JH}$, Huang $\mathrm{CC}$, Kuo CD, Huang $\mathrm{Cl}$, Lee LS: Heart rate variability measures as predictors of in-hospital mortality in ED patients with sepsis. Am J Emerg Med 2008, 26:395-401.

14. Terragni PP, Rosboch G, Tealdi A, Corno E, Menaldo E, Davini O, Gandini G, Herrmann P, Mascia L, Quintel M, Slutsky AS, Gattinoni L, Ranieri VM: Tidal hyperinflation during low tidal volume ventilation in acute respiratory distress syndrome. Am J Respir Crit Care Med 2007, 175:160-166.

15. Cressoni M, Zanella A, Epp M, Corti I, Patroniti N, Kolobow T, Pesenti A Decreasing pulmonary ventilation through bicarbonate ultrafiltration: An experimental study. Crit Care Med 2009, 37:2612-2618.

16. Zanella A, Patroniti N, Isgrò S, Albertini M, Costanzi M, Pirrone F, Scaravilli V, Vergnano B, Pesenti A: Blood acidification enhances carbon dioxide removal of membrane lung: An experimental study. Intensive Care Med 2009, 35:1484-1487.

17. Terragni PP, Del Sorbo L, Mascia L, Urbino R, Martin EL, Birocco A, Faggiano C, Quintel M, Gattinoni L, Ranieri VM: Tidal volume lower than $6 \mathrm{ml} / \mathrm{kg}$ enhances lung protection: Role of extracorporeal carbon dioxide removal. Anesthesiology 2009, 111:826-835.

18. Hamburger M, Robertson OH: Studies on the pathogenesis of experimental pneumococcus pneumonia in the dog: I. secondary pulmonary lesions. Relationship of bronchial obstruction and distribution of pneumococci to their inception. J Exp Med 1940, 72:261-274.

19. Robertson $\mathrm{OH}$, Hamburger M: Studies on the pathogenesis of experimental pneumococcus pneumonia in the dog: II. Secondary pulmonary lesions. Their production by intratracheal and intrabronchial injections of fluid pneumonic exudate. J Exp Med 1940, 72: 275-288.

20. Schortgen F, Bouadma L, Joly-Guillou ML, Ricard JD, Dreyfuss D, Saumon G: Infectious and inflammatory dissemination are affected by ventilation strategy in rats with unilateral pneumonia. Intensive Care Med 2004, 30:693-701.

21. Gupta N, Su X, Popov B, Lee JW, Serikov V, Matthay MA: Intrapulmonary delivery of bone marrow-derived mesenchymal stem cells improves survival and attenuates endotoxin-induced acute lung injury in mice. J Immunol 2007, 179:1855-1863.

22. Lee JW, Fang X, Gupta N, Serikov V, Matthay MA: Allogeneic human mesenchymal stem cells for treatment of E. coli endotoxin-induced acute lung injury in the ex vivo perfused human lung. Proc Natl Acad Sci U S A
2009, 106:16357-16362

23. Hare JM, Traverse JH, Henry TD, Dib N, Strumpf RK, Schulman SP, Gerstenblith G, DeMaria AN, Denktas AE, Gammon RS, Hermiller JB Jr, Reisman MA, Schaer GL, Sherman W: A randomized, double-blind, placebo-controlled, doseescalation study of intravenous adult human mesenchymal stem cells (prochymal) after acute myocardial infarction. J Am Coll Cardiol 2009, 54:2277-2286.

24. Wigginton JG, Pepe PE, Bedolla JP, DeTamble LA, Atkins JM: Sex-related differences in the presentation and outcome of out-of-hospital cardiopulmonary arrest: A multi-year, prospective, population-based study. Crit Care Med 2002, 30:S131-136.

25. Yune TY, Kim SJ, Lee SM, Lee YK, Oh YJ, Kim YC, Markelonis GJ, Oh TH: Systemic administration of 17 -beta-estradiol reduces apoptotic cell death and improves functional recovery following traumatic spinal cord injury in rats. J Neurotrauma 2004, 21:293-306.

26. Hawk T, Zhang YQ, Rajakumar G, Day AL, Simpkins JW: Testosterone increases and estradiol decreases middle cerebral artery occlusion lesion size in male rats. Brain Res 1998, 796:296-298.

27. Barth E, Bassi G, Maybauer DM, Simon F, Gröger M, Oter S, Speit G, Nguyen CD, Hasel C, Möller P, Wachter U, Vogt JA, Matejovic M, Radermacher P, Calzia E: Effects of ventilation with $100 \%$ oxygen during early hyperdynamic porcine fecal peritonitis. Crit Care Med 2008, 36:495-503.

28. Hauser B, Barth E, Bassi G, Simon F, Gröger M, Oter S, Speit G, Ploner F, Möller P, Wachter U, Vogt JA, Matejovic M, Calzia E, Georgieff M, Radermacher P, Maybauer DM: Hemodynamic, metabolic and organ function effects of pure $\mathrm{O}_{2}$ ventilation during established fecal peritonitis-induced septic shock. Crit Care Med 2009, 37:2465-2469.

29. Greif R, Akça O, Horn EP, Kurz A, Sessler Dl; Outcomes Research Group: Supplemental perioperative oxygen to reduce the incidence of surgicalwound infection Outcomes Research Group. N Engl J Med 2000, 342:161-167.

30. Knighton DR, Halliday B, Hunt TK: Oxygen as an antibiotic. The effect of inspired oxygen on infection. Arch Surg 1984, 119:199-204.

31. Kotani N, Hashimoto H, Sessler DI, Muraoka M, Hashiba E, Kubota T, Matsuki A: Supplemental intraoperative oxygen augments antimicrobial and proinflammatory responses of alveolar macrophages. Anesthesiology 2000, 93:15-25.

32. Choi H, Kim SH, Chun YS, Cho YS, Park JW, Kim MS: In vivo hyperoxic preconditioning prevents myocardial infarction by expressing bcl-2. Exp Biol Med 2006, 231:463-472.

33. Singer M: Catecholamine treatment for shock - equally good or bad? Lancet 2007, 370:636-637.

34. Dünser MW, Takala J, Ulmer H, Mayr VD, Luckner G, Jochberger S, Daudel F, Lepper P, Hasibeder WR, Jakob SM: Arterial blood pressure during early sepsis and outcome. Intensive Care Med 2009, 35:1225-1233.

35. Ackland GL, Yao ST, Rudiger A, Dyson A, Stidwill R, Poputnikov D, Singer M, Gourine AV: Cardioprotection, attenuated systemic inflammation, and survival benefit of beta1-adrenoceptor blockade in severe sepsis in rats. Crit Care Med 2010, 38:388-394.

36. Hagiwara S, Iwasaka H, Maeda H, Noguchi T: Landiolol, an ultrashort-acting beta1-adrenoceptor antagonist, has protective effects in an LPS-induced systemic inflammation model. Shock 2009, 31:515-520.

37. Gore DC, Wolfe RR: Hemodynamic and metabolic effects of selective beta-1 adrenergic blockade during sepsis. Surgery 2006, 139:686-694.

38. Schmittinger CA, Dünser MW, Haller M, Ulmer H, Luckner G, Torgersen C, Jochberger S, Hasibeder WR: Combined milrinone and enteral metoprolol therapy in patients with septic myocardial depression. Crit Care 2008, 12:R99.

39. McEwen BS: Protective and damaging effects of stress mediators. N Engl J Med 1998, 338:171-179.

40. Sterling P: Principles of allostasis: Optimal design, predictive regulation, pathophysiology, and rational therapeutics. In Allostasis, Homeostasis, and the Costs of Physiological Adaptation. Edited by Schulkin J. Cambridge, UK: Cambridge University Press; 2004.

41. Wittstein IS, Thiemann DR, Lima JA, Baughman KL, Schulman SP, Gerstenblith G, Wu KC, Rade JJ, Bivalacqua TJ, Champion HC: Neurohumoral features of myocardial stunning due to sudden emotional stress. N Engl J Med 2005, 352:539-548.

42. Selye H: Stress and the general adaptation syndrome. BrMed J 1950, 17:1383-1392.

43. Singer M, De Santis V, Vitale D, Jeffcoate W: Multiorgan failure is an adaptive, 
endocrinemediated, metabolic response to overwhelming systemic inflammation. Lancet 2004, 364:545-548.

44. Friese RS, Bruns B, Sinton CM: Sleep deprivation after septic insult increases mortality independent of age. J Trauma 2009, 66:50-54

45. Girard TD, Jackson JC, Pandharipande PP, Pun BT, Thompson JL, Shintani AK, Gordon SM, Canonico AE, Dittus RS, Bernard GR, Ely EW: Duration of delirium as a predictor of long-term cognitive impairment in survivors of critical illness. Crit Care Med 2010, 38:1513-1520.

46. Sampson EL, Raven PR, Ndhlovu PN, Vallance A, Garlick N, Watts J, Blanchard MR, Bruce A, Blizard R, Ritchie CW: A randomized, double-blind, placebocontrolled trial of donepezil hydrochloride (Aricept) for reducing the incidence of postoperative delirium after elective total hip replacement. Int J Geriatr Psychiatry 2007, 22:343-349.

47. Singer $M$, Glynne P: Treating critical illness: the importance of first doing no harm. PLOS Med 2005, 2:e167.

48. Schweickert WD, Pohlman MC, Pohlman AS, Nigos C, Pawlik AJ, Esbrook CL, Spears L, Miller M, Franczyk M, Deprizio D, Schmidt GA, Bowman A, Barr R, McCallister KE, Hall JB, Kress JP: Early physical and occupational therapy in mechanically ventilated, critically ill patients: A randomised controlled trial. Lancet 2009, 373:1874-1882.

49. Yuan CS, Wei G, Foss JF, O'Connor M, Karrison T, Osinski J: Effects of subcutaneous methylnaltrexone on morphine-induced peripherally mediated side effects: A double-blind randomized placebo-controlled trial. J Pharmacol Exp Ther 2002, 300:118-123.

50. Riker RR, Shehabi Y, Bokesch PM, Ceraso D, Wisemandle W, Koura F, Whitten P, Margolis BD, Byrne DW, Ely EW, Rocha MG; SEDCOM (Safety and Efficacy of Dexmedetomidine Compared With Midazolam) Study Group: Dexmedetomidine vs midazolam for sedation of critically ill patients: A randomized trial. JAMA 2009, 301:489-499.

51. De Jonghe B, Sharshar T, Lefaucheur JP, Authier FJ, Durand-Zaleski I, Boussarsar M, Cerf C, Renaud E, Mesrati F, Carlet J, Raphaël JC, Outin H, Bastuji-Garin S; Groupe de Réflexion et d'Etude des Neuromyopathies en Réanimation: Paresis acquired in the intensive care unit: A prospective multicenter study. JAMA 2002, 288:2859-2867.

52. Léger B, Senese R, Al-Khodairy AW, Dériaz O, Gobelet C, Giacobino JP, Russell AP: Atrogin-1, MuRF1, and FoXO, as well as phosphorylated GSK-3beta and $4 \mathrm{E}-\mathrm{BP} 1$ are reduced in skeletal muscle of chronic spinal cord-injured patients. Muscle Nerve 2009, 40:69-78.
53. Bhasin S, Storer TW, Berman N, Callegari C, Clevenger B, Phillips J, Bunnell TJ, Tricker R, Shirazi A, Casaburi R: The effects of supraphysiologic doses of testosterone on muscle size and strength in normal men. $N$ Engl $J$ Med 1996, 335:1-7.

54. Vivodtzev I, Pépin JL, Vottero G, Mayer V, Porsin B, Lévy P, Wuyam B: Improvement in quadriceps strength and dyspnea in daily tasks after 1 month of electrical stimulation in severely deconditioned and malnourished COPD. Chest 2006, 129:1540-1548.

55. Ospina-Tascon GA, Buchele GL, Vincent JL: Multicenter, randomized, controlled trials evaluating mortality in intensive care: Doomed to fail? Crit Care Med 2008, 36:1311-1322.

56. Moreno RP, Metnitz PG, Almeida E, Jordan B, Bauer P, Campos RA, lapichino G, Edbrooke D, Capuzzo M, Le Gall JR; SAPS 3 Investigators: SAPS 3. From evaluation of the patient to evaluation of the intensive care unit. Part 2 : Development of a prognostic model for hospital mortality at ICU admission. Intensive Care Med 2005, 31:1345-1355.

57. Moreno RP, Metnitz B, Adler L, Hoechtl A, Bauer P, Metnitz PG; SAPS 3 Investigators: Sepsis mortality prediction based on predisposition, infection and response. Intensive Care Med 2008, 34:496-504

58. Benson K, Hartz AJ: A comparison of observational studies and randomized, controlled trials. N Eng/ J Med 2000, 342:1878-1886.

59. Concato J, Shah N, Horwitz RI: Randomized, controlled trials, observational studies, and the hierarchy of research designs. N Engl J Med 2000, 342:1887-1892.

60. Cresci G, Cue J: The patient with circulatory shock: to feed or not to feed? Nutr Clin Pract 2008, 23:501-509.

61. Pronovost PJ, Jenckes MW, Dorman T, Garrett E, Breslow MJ, Rosenfeld BA, Lipsett PA, Bass E: Organizational characteristics of intensive care units related to outcomes of abdominal aortic surgery. JAMA 1999, 281:1310-1317.

doi:10.1186/cc10245

Cite this article as: Singer M, Matthay MA: Clinical review: Thinking outside the box - an iconoclastic view of current practice. Critical Care 2011, 15:225. 